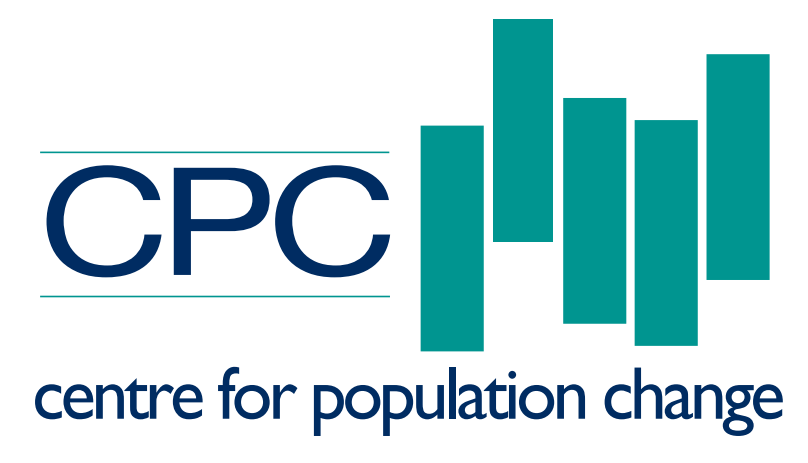

Scenarios of population change in the coastal

Ganges Brahmaputra delta (2011 - 2051)

Sylvia Szabo

Dilruba Begum

Sate Ahmad

Zoe Matthews

Peter Kim Streatfield 


\section{ABSTRACT}

This paper provides an overview of population dynamics and scenarios of population change in the environmentally vulnerable coastal Ganges Brahmaputra Delta region. The main data sources used for the study include the historical and most recent Census data, data from Sample Vital Registration System (SVRS) and Demographic and Health Surveys (DHS). The research adopts the standard cohort component approach for population projections and provides population estimates for the period 2011-2051. The results include scenarios of future population change in the coastal Ganges Brahmaputra Delta (GBD) and district-level population projections by age and sex. The results show that population growth is likely to continue in some, but not all, districts in the study area. The findings also suggest that migration is most likely to be the deciding component of population change in the region. The paper concludes by discussing selected policy implications in the context of expected changes in population structure in the Ganges Brahmaputra Delta, including population aging and rapid urbanisation in some districts.

\section{KEYWORDS}

Population projections, Ganges Brahmaputra Delta, Bangladesh

\section{EDITORIAL NOTE}

Dr Sylvia Szabo is a Research Fellow in the Division of Social Statistics and Demography at the University of Southampton.

Dilruba Begum is a Senior Research Officer at the International Centre for Diarrhoeal Disease Research, Bangladesh (icddr,b).

Sate Ahmad is a Research Officer at the International Centre for Diarrhoeal Disease Research, Bangladesh (icddr,b).

Professor Zoe Matthews is Professor of Global Health and Social Statistics in the Division of Social Statistics and Demography at the University of Southampton.

Dr Peter Kim Streatfield is a Director at the International Centre for Diarrhoeal Disease Research, Bangladesh (icddr,b).

Corresponding author: Dr Sylvia Szabo,s.m.szabo@southampton.ac.uk. 


\section{ACKNOWLEDGEMENTS}

This research is part of the BF-DELTAS project "Catalysing action towards sustainability of deltaic systems" funded by the Belmont Forum (grant number NE/L008726/1) and it contributes to the International Council of Science (ICSU) "Sustainable Deltas 2015" Initiative which aims to increase awareness, research collaboration, and data/model sharing towards delta sustainability. This research was also supported by the ESPA Deltas project (grant number NE/J002755/1). The Ecosystem Services for Poverty Alleviation (ESPA) programme is funded by the Department for International Development (DFID), the Economic and Social Research Council (ESRC) and the Natural Environment Research Council (NERC).

(C) Sylvia Szabo, Dilruba Begum, State Ahmad, Zoe Matthews and Peter Kim Streatfield all rights reserved. Short sections of text, not to exceed two paragraphs, may be quoted without explicit permission provided that full credit, including (c) notice, is given to the source.

\section{ESRC Centre for Population Change}

The ESRC Centre for Population Change (CPC) is a joint initiative between the Universities of Southampton, St Andrews, Edinburgh, Stirling, Strathclyde, in partnership with the Office for National Statistics (ONS) and the National Records of Scotland (NRS). The Centre is funded by the Economic and Social Research Council (ESRC) grant numbers RES-625-28-0001 and ES/K007394/1.

This working paper series publishes independent research, not always funded through the Centre. The views and opinions expressed by authors do not necessarily reflect those of the CPC, ESRC, ONS or NRS.

The Working Paper Series is edited by Teresa McGowan.

\section{Website | Email | Twitter $\mid$ Facebook $\mid$ Mendeley}




\title{
SCENARIOS OF POPULATION CHANGE IN THE COASTAL GANGES BRAHMAPUTRA DELTA \\ (2011-2051)
}

\author{
TABLE OF CONTENTS
}

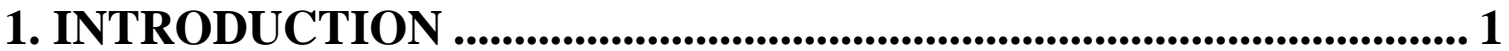

2. POPULATION DYNAMICS IN THE DELTA STUDY

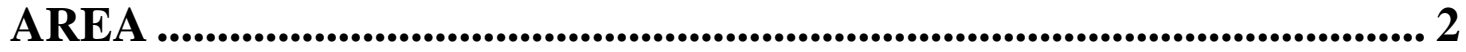

3. DATA AND ASSUMPTIONS ........................................................ 4

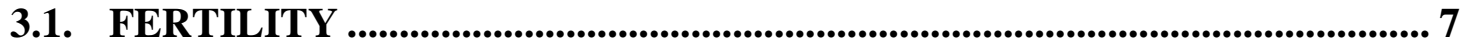

3.2. MORTALITY ................................................................................................... 11

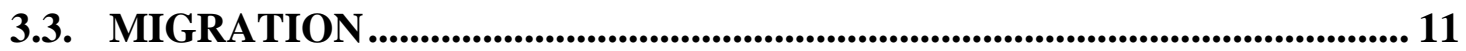

4. SCENARIOS OF FUTURE POPULATION CHANGE...................... 13

4.1. OVERVIEW OF THE THREE SCENARIOS ................................................. 13

4.2. POPULATION STRUCTURE, DEPENDENCY RATIO AND

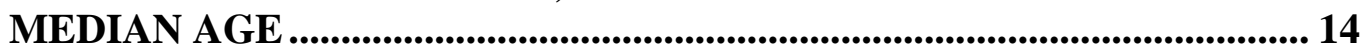

5. CONCLUSIONS AND POLICY IMPLICATIONS ......................... 17

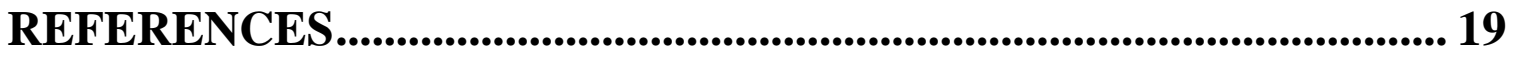

6. APPENDIX A 


\section{INTRODUCTION}

Since the publication of the First Essay by T.R. Malthus (1798), population dynamics and the interlinkages between population and access to vital resources have been a subject of intense scholarly inquiry. Today, the fears that population growth may threaten adequate food supplies have regained ground, in particular in the context of the studies on food security (Brown, 2012; Dyson \& Grada, 2002; Ehrlich, Ehrlich, \& Daily, 1993; FAO, 2013; FAO, IFAD, \& WFP, 2013; Funk \& Brown, 2009; Pimentel, Huang, Cordova, \& Pimentel, 1997). Populations of most developing regions continue to grow despite declining fertility rates. In many countries, such as China and Iran, population momentum will be a major factor contributing to the future population size. At the same time, the expected fruits of demographic transition could be hindered by potential shortage of vital resources, such as food and water. Given the frequency and scale of natural disasters and the increasing threats posed by climate change, it is timely to focus scholarly attention on the populous areas in environmentally vulnerable delta regions, such as the Bangladeshi Ganges Brahmaputra Delta.

Between 1950 and 2010 the population of Bangladesh has increased approximately four times and it is projected to exceed 200 million by 2050 (UN, 2013). This large population size coupled with high population density and unplanned urbanisation puts considerable pressures on agriculture which has limited capacity for expanding production of food (Streatfield \& Karar, 2008). The vulnerable socio-ecological system of the delta region has been changing rapidly due to factors such as population growth, sea level rise and changing land use (Hossain, Dearing, Rahman, \& Salehin, 2014). Evidence suggests that households living in the coastal areas of the Ganges Brahmaputra Delta have been particularly at risk in terms of sustaining their livelihoods. For example, a recent report by the Ministry of Environment and Forest (MOEF) stated that the coastal areas are more vulnerable to the impact of climate change compared to other regions of Bangladesh (MOEF, 2005). This vulnerability in turn translates into an increased risk of yield reduction in the agricultural sector (MOEF, 2005). Coupled with soil salinity linked to shrimp farming, (Swapan \& Gavin, 2011) the assessment of future population dynamics should be considered a priority in sustainable development research agendas. 
Although environmental research focusing on the Ganges Brahmaputra Delta as well as on other delta regions is relatively rich, we found that there is a surprising lack of robust, up to date demographic analysis and demographic projections for the region. Yet, in order for policy makers to meet increasingly complex challenges in the delta, it is crucial to understand the dynamics of population change and estimate the future population stock. The study area covers nine districts; three in Khulna division and six in Barisal division. Khulna division has already reached the below replacement total fertility rate (TFR) of 1.9, while in Barisal division TFR is 2.3, a decrease from 3.47 in 1993-94 (Mitra, Ali, Islam, Cross, \& Saha, 1994; NIPORT, Mitra and Associates, \& ICF International, 2013). These changing demographic patterns require thorough investigation, in particular in the context of assessing future resource needs and resilience strategies in this vulnerable region. In this context, the main objective of the present study is to provide a new set of population projections for the Ganges Brahmaputra Delta based on a set of justified assumptions regarding future fertility, mortality and migration. The analysis responds directly to a call for population projections raised by development scholars (Streatfield \& Karar, 2008).

The next section provides a brief overview of the past and current demographic trends in the Ganges Brahmaputra Delta. We then discuss the methods and data sources, including assumptions made. In section four, we present and discuss the selected projections scenarios. The final section focuses on the implications for the region's food security challenges, limitations of the study and implications for policy and practice.

\section{POPULATION DYNAMICS IN THE DELTA STUDY AREA}

According to the results of 2011 Population and Housing Census, the enumerated population of Bangladesh in 2011 was 144 million with an average of 964 inhabitants per square kilometre (the density in 2001 was 834). The total population of the study area (nine districts) is about 14 million comprising approximately 10 per cent of the whole country's population. Bangladesh has one of the highest population densities in the world. In the study region, however, the density is 
lower. For example, Barisal division has a density of 630 people per square km while Dhaka division has a density of 1,521 people per square $\mathrm{km}$.

The population of Bangladesh grew rapidly over the past century. As highlighted previously, the country is now experiencing a demographic transition and the continuous decline of the natural growth rate should lead to a lower population increase in the coming decades. Compared to the adjusted population in 2001, the population size in 2011 was greater by approximately 14 million people, which represents a 10.8 per cent increase in population size over the intercensal period and involves an average annual growth rate of 1.47 per cent. Table 1 illustrates population change in the study area. At the district level, there is a large variation in the change in population size during the last intercensal period (2001-2011). While in 2001 all districts in the study area experienced a positive annual growth rate, in 2011 this pattern has changed. Notably, Barisal, Jhalakathi, Bagerhat and Khulna had negative rates of population growth. Largest changes can be observed in the Khulna division, where Bagerhat and Khulna districts together lost more than 133 thousand people.

Finally, analysing trends in the total fertility rate (TFR) in Bangladesh reveals a decline from 6.7 children per woman in 1960 to around 2.2 in 2012 (World Bank, 2012). This decline is substantial in urban and rural areas and across all administrative units, education categories, and wealth quintiles. Fertility decline is also more pronounced for women from the wealthier households than for women from the poorer households (NIPORT et al., 2013). Investigation of the age pattern of fertility shows that fertility has declined substantially among all age groups. Between 2001 and 2010, the fertility decline has been smallest for the 20-24 age group (14 percent) and largest for the oldest age group 45-49 (67 percent). The average total fertility rates in both Khulna and Barisal divisions are below the national average except for Barisal district. The lowest fertility rates are observed in Satkhira and Barguna districts with TFR 1.56 and 1.59 respectively (BBS, SID, \& Ministry of Planning, 2012). Despite these trends, Bangladesh's population is likely to continue to see an increase in population size before stabilizing. Discussion of fertility rates in the study area will be further undertaken in the next section. 


\begin{tabular}{|l|l|c|c|c|c|}
\hline \multicolumn{2}{|c|}{ Administrative area } & \multicolumn{2}{c|}{ Population size } & \multicolumn{2}{c|}{ Annual growth rate } \\
\hline Division & district & $\mathbf{2 0 0 1}$ & $\mathbf{2 0 1 1}$ & $\mathbf{2 0 0 1}$ & $\mathbf{2 0 1 1}$ \\
\hline \multirow{5}{*}{ Barisal } & Barguna & 848,554 & 892,781 & 0.90 & 0.50 \\
& Barisal & $2,355,967$ & $2,324,310$ & 0.65 & -0.13 \\
& Bhola & $1,703,117$ & $1,776,795$ & 1.44 & 0.42 \\
& Jhalakathi & 694,231 & 682,669 & 0.41 & -0.17 \\
& Patuakhali & $1,460,781$ & $1,535,854$ & 1.38 & 0.49 \\
& Pirojpur & $1,111,068$ & $1,113,257$ & 0.44 & 0.02 \\
\hline \multirow{4}{*}{ Khulna } & Bagerhat & $1,549,031$ & $1,476,090$ & 0.79 & -0.47 \\
& Khulna & $2,378,971$ & $2,318,527$ & 1.70 & -0.25 \\
\hline Total study area & Shatkhira & $1,864,704$ & $1,985,959$ & 1.56 & 0.62 \\
\hline
\end{tabular}

Table 1: Population change in the study area (2001-2011).

Source: Bangladesh Population and Housing Census (2001 and 2011).

\section{DATA AND ASSUMPTIONS}

For the purpose of this research several data sources have been used. The primary source of the data was the most recent 2011 Bangladesh Population and Housing Census. The Census results included the detailed district-level reports, the Socio-Economic and Demographic report published by the Bangladesh Bureau of Statistics, and raw data available as Excel file. Complementary sources of data included the most recent and previous versions of the Demographic Health Surveys (DHS), the 2010 report on the Sample Vital Registration System (SVRS) and statistics developed by the UN Population Division. Additional data were drawn from relevant literature, government reports as well as reports by international organisations. This section presents the key population statistics for the nine districts in the study area organised by divisions. It then discusses the assumption made for conducting population projections.

Table 2 summarises the population distribution in the study area by district. Khulna and Barisal are the most populous districts while Jhalokathi and Barguna have the smallest populations. In terms of the density of population, with 966 people per square kilometre, 
Jhalokhathi district has the highest population density while Bagerhat district in Barisal has lowest population density (373 people per square kilometre). There are also large differentials amongst districts regarding socio-economic indicators, urbanisation levels and sex ratio. For example, the sex ratio in Jhalokathi district is 93 (92 in rural areas), while the sex ratio in Khulna is 103 (108 in urban areas). Although ideally projections should consider the lowest level of disaggregation, data availability often prevents researchers from using most relevant data. Accounting for these potential limitations, the remainder of this section focuses on discussing assumptions made for conducting population projections in the study area. 


\begin{tabular}{|c|c|c|c|c|c|c|c|c|c|}
\hline \multirow[b]{2}{*}{ Age groups } & \multicolumn{3}{|c|}{ Khulna division } & \multicolumn{6}{|c|}{ Barisal division } \\
\hline & Bagerhat & Khulna & Satkhira & Barguna & Barisal & Bhola & Jhalokathi & Patuakhali & Pirojpur \\
\hline $0-4$ & 132,715 & 197,075 & 170,622 & 88,297 & 228,010 & 214,777 & 63,488 & 159,889 & 106,980 \\
\hline $5-9$ & 169,581 & 241,127 & 216,253 & 110,594 & 300,136 & 269,803 & 85,334 & 206,010 & 135,953 \\
\hline $10-14$ & 174,005 & 252,719 & 218,237 & 102,567 & 302,463 & 237,853 & 89,430 & 189,099 & 134,839 \\
\hline $15-19$ & 119,444 & 206,349 & 178,558 & 63,324 & 209,397 & 150,877 & 60,075 & 119,917 & 94,722 \\
\hline $20-24$ & 117,969 & 224,897 & 182,526 & 68,675 & 186,131 & 142,002 & 49,835 & 118,379 & 88,035 \\
\hline $25-29$ & 126,817 & 222,579 & 184,510 & 81,162 & 186,131 & 150,877 & 51,200 & 132,216 & 90,264 \\
\hline $30-34$ & 115,095 & 185,797 & 156,624 & 68,685 & 162,378 & 112,133 & 49,287 & 110,533 & 81,796 \\
\hline 35-39 & 104,619 & 168,886 & 142,368 & 62,766 & 148,384 & 102,469 & 45,039 & 101,007 & 74,746 \\
\hline $40-44$ & 94,143 & 151,975 & 128,112 & 54,403 & 128,614 & 88,817 & 39,039 & 87,550 & 64,788 \\
\hline $45-49$ & 72,493 & 117,025 & 98,650 & 42,470 & 100,403 & 69,335 & 30,476 & 68,346 & 50,577 \\
\hline $50-54$ & 63,347 & 95,507 & 81,726 & 37,589 & 91,432 & 57,623 & 28,772 & 60,416 & 46,331 \\
\hline $55-59$ & 44,300 & 66,790 & 57,152 & 28,411 & 69,106 & 43,553 & 21,746 & 45,664 & 35,018 \\
\hline $60-64$ & 48,662 & 64,919 & 57,535 & 30,324 & 76,779 & 51,476 & 23,893 & 50,734 & 36,774 \\
\hline $65-69$ & 34,888 & 46,147 & 42,468 & 19,693 & 49,660 & 31,354 & 16,581 & 31,683 & 26,656 \\
\hline $70-74$ & 26,315 & 34,808 & 32,033 & 14,128 & 35,625 & 22,493 & 11,895 & 22,729 & 19,123 \\
\hline $75-79$ & 15,749 & 20,832 & 19,171 & 8,669 & 21,861 & 13,803 & 7,299 & 13,947 & 11,734 \\
\hline $80+$ & 15,949 & 21,096 & 19,414 & 11,024 & 27,799 & 17,551 & 9,282 & 17,735 & 14,921 \\
\hline Total & $1,476,090$ & $2,318,527$ & $1,985,959$ & 892,781 & $2,324,310$ & $1,776,795$ & 682,669 & $1,535,854$ & $1,113,257$ \\
\hline
\end{tabular}

Table 2: Age distribution of the population in the study area, by district, 2010-11.

Note: Analysis based on the 2011 Bangladesh Population Census. 39-50 and 65+ age group distribution has been derived based on equivalent proportions in SVRS report (BBS, 2011). 


\subsection{FERTILITY}

Because of the unavailability of longitudinal data at the district level, division level historical trends in total fertility rates have been analysed using DHS reports. Bangladeshi DHS is a rich source of fertility and health indicators dating from 1993/94. As shown in Figure 3.1, in line with the national trends, total fertility rates in the study area have seen a considerable decline. In Barisal, the TFR was as high as 3.47 in 1993/94, while in Khulna TFR was 3.05 during the same time. This compares to the national TFR of 3.44 (urban TFR was 2.69, while rural TFR was 3.54). Whereas in Barisal, the TFR dropped to 2.3 by 2011, in Khulna the current (2011) TFR is well below the replacement level (overall TFR=1.9). Moreover, the most recent Census data suggest that in some districts such as Satkhira, TFR is as low as 1.56. In other districts of Khulna division, which are under the study area, the TFRs are 1.63 (Khulna district) and 1.76 (Bagerhat). In this context, it is interesting to mention the changes in the ideal family size in Ganges Brahmaputra delta region.

During the time of the first DHS (1993/94) the mean ideal number of children ${ }^{1}$ was 2.5, a decline from 4.1 in 1975 (Mitra et al. 1994). Reflecting the reported TFR data, Khulna division showed lowest desired mean family size with 2.3 children compared to 2.4-2.8 in other divisions. According to the most recent 2011 DHS report the mean ideal number of children dropped to 2.2. Regarding regional differentials, Khulna division continues to have both lowest fertility rates and mean ideal number of children (2.0), followed by Barisal, Dhaka, Rajshahi and Rangpur, where the mean ideal number of children is 2.1 .

1 In order to assess the ideal number of children, DHS asked the interviewed women two questions. These included "If you could choose exactly the number of children to have in your whole life, how many would that be?" For women who had children, the question was rephrased as follows: "If you could go back to the time you did not have any children and could choose exactly the number of children to have in your whole life, how many would that be?" (Mitra et al., 1994) 


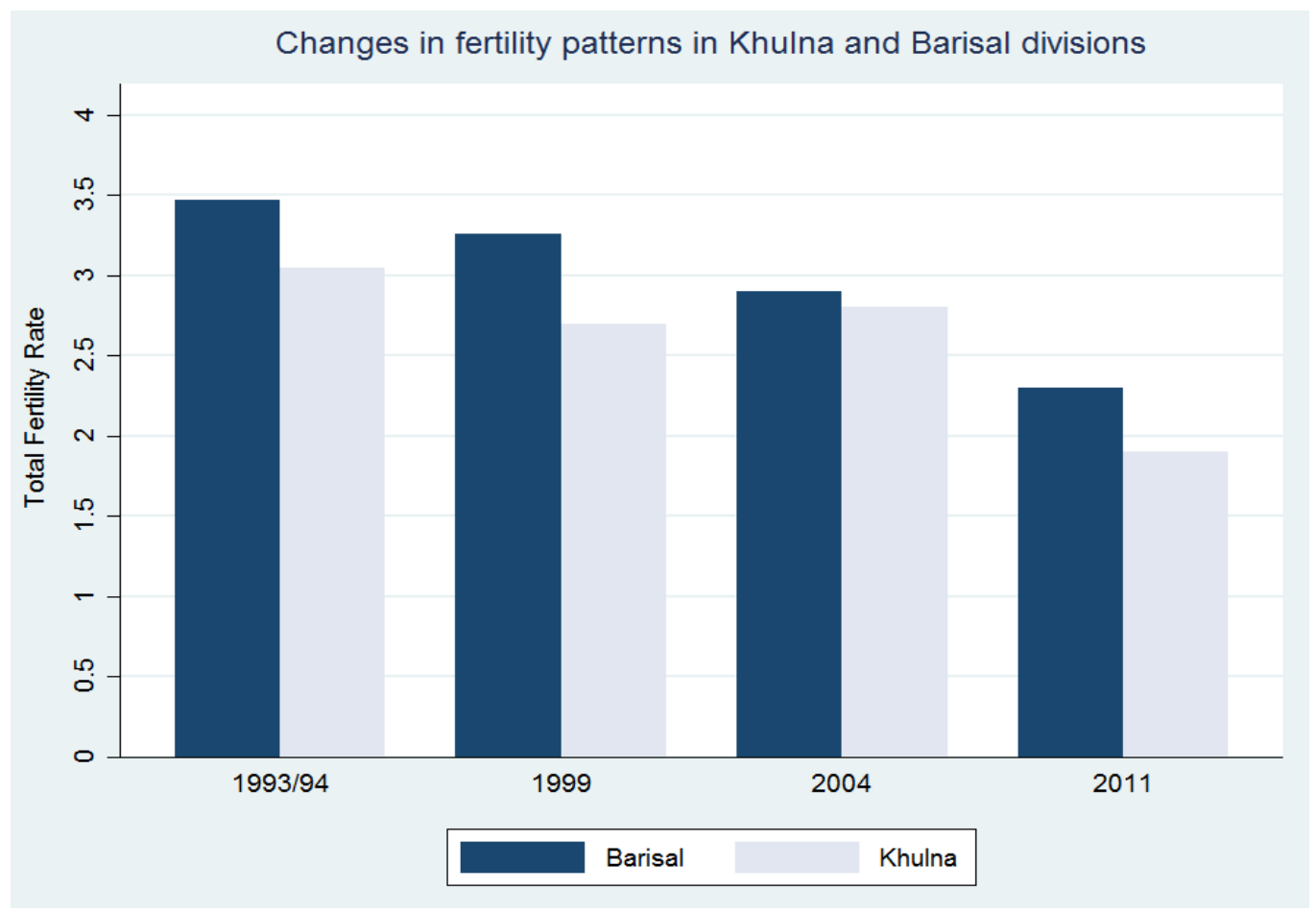

Figure 1: Fertility trends in Barisal and Khulna divisions.

Overall, demographic research distinguishes between three low fertility levels. Firstly, the replacement level with TFR of 2.1 children per women, secondly very low fertility where TFR is 1.5, and finally, lowest-low, or ultra-low fertility with TFR of 1.3 or below (Billari \& Kohler, 2004; Jones, 2009; Suzuki, 2009). While the aforementioned fertility levels have primarily been analysed in the context of Europe and Asia-Pacific, the trends and current fertility levels in the Ganges Brahmaputra delta show similar patterns. For example, Jones et al. (2008) pointed out that Japan started considering fertility boosting measures when its TFR reached 1.57. In a country like Bangladesh, traditionally associated with population growth and high population density, the fertility trends in the coastal delta deserve particular attention.

In order to conduct population projections, data measuring age specific fertility rates (ASFRs) are required. ASFRs are essential to carrying out demographic analyses because they allow accounting for the distribution of births across different age groups of women. The 2011 SocioEconomic report (BBS, 2012) based on the most recent census data provides fertility schedules by districts as well as by place of residence (urban vs. rural). The original ASFRs have been 
converted into percentage distributions and are presented in Table 3, which summarizes fertility distribution by age groups across all districts in the study area. It can be observed that in Satkhira and Khulna districts the contribution of fertility to the overall TFR by the youngest women (1519) is the greatest, while in Jhalokati and Pirojpur women aged 40 and older contribute most to TFRs in their respective districts.

Finally, population projections require not only the most recent data, but also the assumptions pertaining to the expected future fertility trends. Thus, based on the historical fertility data, policy developments and evolution of fertility preferences, the present research applies two sets of fertility assumptions. First, the constant trend in fertility is assumed, second, fertility is assumed to continue to decline based on the past fertility trends and fertility preferences. The constant fertility assumption is used to enable comparison with the outcomes of projections based on alternative assumptions. To calculate the declining trends in TFR assumption, we base our interpolation on past patterns at the district level and by applying a threshold of 1.5. We assume that ASFR's will remain the same in the constant and less sustainable scenario while in the more sustainable scenario, they will change following the Pirojpur district pattern. 


\begin{tabular}{|l|c|c|c|c|c|c|c|c|c|}
\hline Age groups & Barguna & Barisal & Bhola & Jhalokati & Patuakhali & Pirojpur & Bagerhat & Khulna & Satkhira \\
\hline $15-19$ & 6.94 & 6.94 & 7.04 & 4.67 & 7.64 & 9.83 & 11.05 & 12.31 & 15.06 \\
$20-24$ & 42.27 & 33.01 & 31.41 & 38.01 & 30.79 & 24.72 & 37.96 & 38.15 & 40.06 \\
$25-29$ & 25.55 & 27.27 & 34.17 & 25.86 & 25.46 & 27.53 & 25.50 & 24.62 & 24.36 \\
$30-34$ & 16.40 & 19.14 & 18.34 & 14.64 & 22.69 & 16.29 & 17.28 & 17.23 & 12.50 \\
$35-39$ & 5.68 & 10.29 & 5.03 & 11.21 & 9.26 & 14.89 & 4.25 & 5.85 & 3.85 \\
$40-44$ & 0.00 & 2.63 & 2.01 & 5.61 & 3.24 & 4.78 & 2.83 & 1.85 & 4.17 \\
$45-49$ & 3.15 & 0.72 & 2.01 & 0.00 & 0.93 & 1.97 & 1.13 & 0.00 & 0.00 \\
total & 100.00 & 100.00 & 100.00 & 100.00 & 100.00 & 100.00 & 100.00 & 100.00 & 100.00 \\
\hline TFR & $\mathbf{1 . 5 9}$ & $\mathbf{2 . 0 9}$ & $\mathbf{1 . 9 9}$ & $\mathbf{1 . 6 1}$ & $\mathbf{2 . 1 6}$ & $\mathbf{1 . 7 7}$ & $\mathbf{1 . 7 6}$ & $\mathbf{1 . 6 3}$ & $\mathbf{1 . 5 3}$ \\
\hline
\end{tabular}

Table 3: Distribution of fertility by age groups.

Source: Authors analysis based on the 2011 Bangladesh Population and Housing Census. 


\subsection{MORTALITY}

Mortality is the second key aspect influencing population change. Bangladesh has experienced important declines in mortality rates resulting in higher life expectancy across all regions. According to the United Nations data, overall life expectancy in Bangladesh increased from 43.6 in 1950-55 to 68.4 in 2005-10. Based on the mortality data from the most recent population Census, the estimated current life expectancy of males in the study area varies from 70.9 for Khulna division to 68.2 in Barisal division. Complementary, for females, life expectancy at birth is 73.1 in Khulna and 69.8 in Barisal. While historical data are difficult to find, a paper by Sen and Ali (2005) provides statistics on division level life expectancy in 1995. According to these data, at that time life expectancy in Barisal was 57.2 and life expectancy in Khulna was 58.4. Based on these data and accounting for trends in other development indicators it is reasonable to assume that life expectancy in the Ganges Brahmaputra delta is likely to further increase. Existing data are therefore extrapolated based on the division level changes in mortality.

\subsection{MIGRATION}

Migration is arguably the most complex and challenging component of population change because it is influenced by a number of often unpredictable factors. Because of environmental vulnerability of the coastal Ganges-Brahmaputra delta, the potential for out migration is relatively higher. Push factors might involve poor quality of life, or loss of income due to environmental shocks. Accounting for the fact that migration is relatively difficult to model; the present study makes three district assumptions about migration. In the constant trends scenario, net migration rate and associated number of migrants are based on the past migration trends. In the more sustainable scenario, a decreasing rate of out migration is assumed using interpolation methods. Conversely, in the less sustainable scenario relatively high out migration trends are assumed, based on the most recent 2011 Census data. After two decades, out migration is assumed to gradually decrease. This scenario presupposes a negative impact of climate change, including sea level rise and salinity intrusion, which is likely to exacerbate the existing push factors. A summary of assumptions for migration, mortality and fertility is provided in Table 4 . 


\begin{tabular}{|c|c|c|c|}
\hline ASSUMPTIONS & Fertility & Mortality & Migration \\
\hline $\begin{array}{l}\text { Scenario } 1 \\
\text { (constant) }\end{array}$ & Constant & Constant & $\begin{array}{l}\text { Based on past trends } \\
\text { (current NRI in 2011, } \\
\text { thereafter average of } \\
2001 \text { and } 2011 \text { NMR), } \\
\text { Constant ASMRs }\end{array}$ \\
\hline $\begin{array}{l}\text { Scenario } 2 \\
\text { (more sustainable) }\end{array}$ & $\begin{array}{l}\text { Declining in all } \\
\text { districts, } \\
\text { threshold: } \\
\text { TFR=1.5, } \\
\text { Changing } \\
\text { ASFRs based } \\
\text { on Pirojpur } \\
\text { pattern }\end{array}$ & $\begin{array}{l}\text { Declining with the } \\
\text { following threshold: } \\
\mathrm{LE}=78 \text { for males and } \\
80 \text { for females }\end{array}$ & $\begin{array}{l}\begin{array}{l}\text { Decreasing } \\
\text { migration } \\
\text { reaching } 0 \text { by } \\
\text { century), } \\
\text { (NRI }\end{array} \\
\text { Constant ASMRs }\end{array}$ \\
\hline $\begin{array}{l}\text { Scenario } 3 \\
\text { (less sustainable) } \\
\text { [high out migration, could } \\
\text { involve impact of climate } \\
\text { change] }\end{array}$ & $\begin{array}{l}\text { Declining in all } \\
\text { districts, } \\
\text { threshold: } \\
\text { TFR=1.5, } \\
\text { Constant } \\
\text { ASFRs }\end{array}$ & Constant & $\begin{array}{l}\text { High out migration } \\
\text { (current rate until } \\
2031, \text { decreasing } \\
\text { thereafter), } \\
\text { Changing ASMRs based } \\
\text { on Matlab pattern }\end{array}$ \\
\hline
\end{tabular}

Table 4: Summary of assumptions. 


\section{SCENARIOS OF FUTURE POPULATION CHANGE}

\subsection{OVERVIEW OF THE THREE SCENARIOS}

This section presents three selected scenarios of future population change based on the previously discussed set of assumptions. Table 5 summarises the projected population size for the constant, more sustainable and less sustainable scenarios, while Figure 2 illustrates these trends. The difference in expected population sizes between the constant and more sustainable scenarios is almost 1.3 million people in 2051. This gap is primarily due to the assumption of continuing out migration from the study area under the constant scenario. Interestingly, under the more sustainable scenario, there is very little variation in terms of future population change. The effects of declining out migration combined with higher life expectancy and changing ASFRs lead to practically no change in the projected population size. The starkest difference occurs when the less sustainable scenario is considered. Applying the most recent (2010/11) rate of net migration combined with no improvements in mortality leads to a considerable decrease in the delta population. More specifically, the population size decreases to 13.1 million in 2031 reaching around 11.4 million in 2051. It is important to highlight that the effects of high out migration are not related solely to the number of people who leave a certain area. A high rate of out migration also implies that there would be potentially less women of reproductive age, which in turn has considerable impact on the number of births.

\begin{tabular}{|c|c|c|c|c|c|c|c|c|c|c|}
\hline Area & 2011 & 2016 & 2021 & 2026 & 2031 & 2036 & 2041 & 2046 & 2051 & $\begin{array}{l}\% \text { change } \\
(2011- \\
2051) \\
\end{array}$ \\
\hline $\begin{array}{l}\text { More } \\
\text { sustainable }\end{array}$ & $14,106,242$ & $14,108,562$ & $14,030,651$ & $14,021,038$ & $14,102,600$ & $14,236,335$ & $14,294,783$ & $14,268,882$ & $14,161,440$ & $0.4 \%$ \\
\hline $\begin{array}{l}\text { Less } \\
\text { sustainable }\end{array}$ & $14,106,242$ & $14,040,870$ & $13,788,501$ & $13,484,356$ & $13,148,726$ & $12,732,769$ & $12,305,516$ & $11,838,135$ & $11,357,150$ & $-19.5 \%$ \\
\hline Constant & $14,106,242$ & $14,064,703$ & $14,107,618$ & $14,141,168$ & $14,183,383$ & $14,183,127$ & $13,991,248$ & $13,558,890$ & $12,910,194$ & $-8.5 \%$ \\
\hline
\end{tabular}

Table 5: Estimated population change in the study area. 


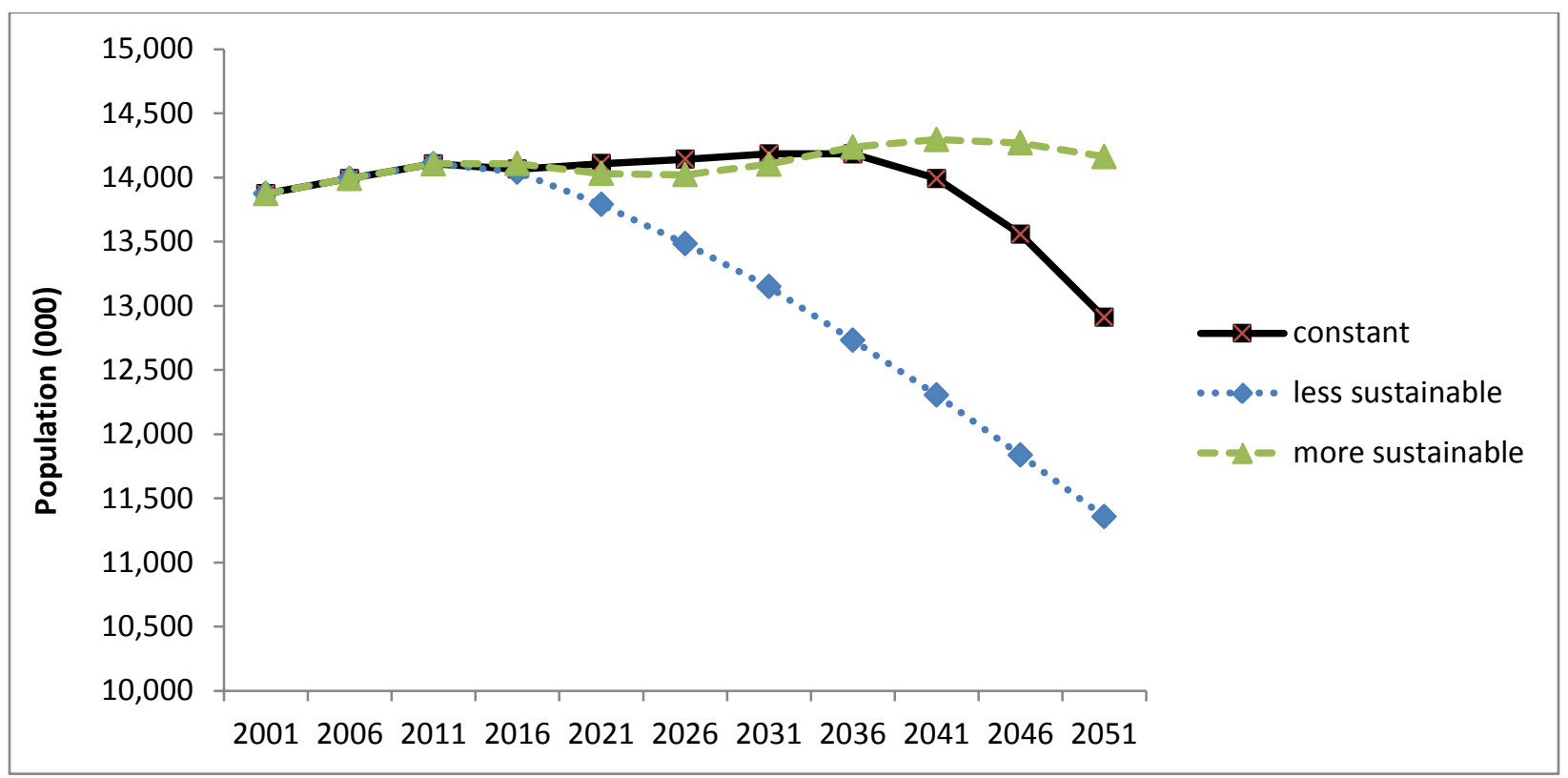

Figure 2: Scenarios of population change in the study area.

\subsection{POPULATION STRUCTURE, DEPENDENCY RATIO AND MEDIAN AGE}

The results of the analysis indicate that while population size is likely to vary depending on assumptions made, there is little difference in terms of projected population structure in the study area. It is expected that in the next decades the population structure in the coastal Ganges Brahmaputra delta will undergo considerable change regardless of the projection scenario. These future demographic trends can be explained by declining fertility, greater life expectancy and high rates of out migration. The two key aspects of this shift will entail an aging population and a declining proportion of younger people. More specifically, the proportion of the population aged 65 and over is likely to increase from 5.7 per cent in 2011 to 15 or 16 per cent in 2051 depending on the projection scenario. At the same time, the proportion of children and youth (ages 0-14) will decline from 34 per cent to 15 per cent under the less sustainable scenario and 16 per cent under the constant and more sustainable scenarios. A similar shift is likely to occur in all nine districts although at varying pace.

Figure 3 illustrates the changing population structure by means of population pyramids. It can be noticed that during the projection period the structure of the population in the study area is likely to undergo considerable change. In particular, it can be observed that youngest age 
groups will shrink and be offset by elderly population. Projected dependency ratios and median population age (Appendix A) confirm this pattern. An interesting finding is that initially dependency ratios show a steady decline which is related to the shrinking population at the bottom of the population pyramid. However, before the mid-point of the projection period (between 2026 and 2031), in all three scenarios, the dependency ratios start to pick up which is a consequence of the ageing population. This is confirmed by trends in the median age. While currently the median age in the study area is around 25 years, it is projected to exceed 32 years in 2031 and reach 43 years in 2051. For comparison, according to the Central Intelligence Agency (CIA, 2015), the current median age in Thailand is around 36 years, and in China it is almost 37 years. It should be stressed that these expected changes have important policy and operational implications. In general, an aging population requires a greater support network and care, which is already a challenge in Bangladesh. In this context, national development plans should specifically address the anticipated impacts of population changes at the regional level so as to mitigate future societal risks. 

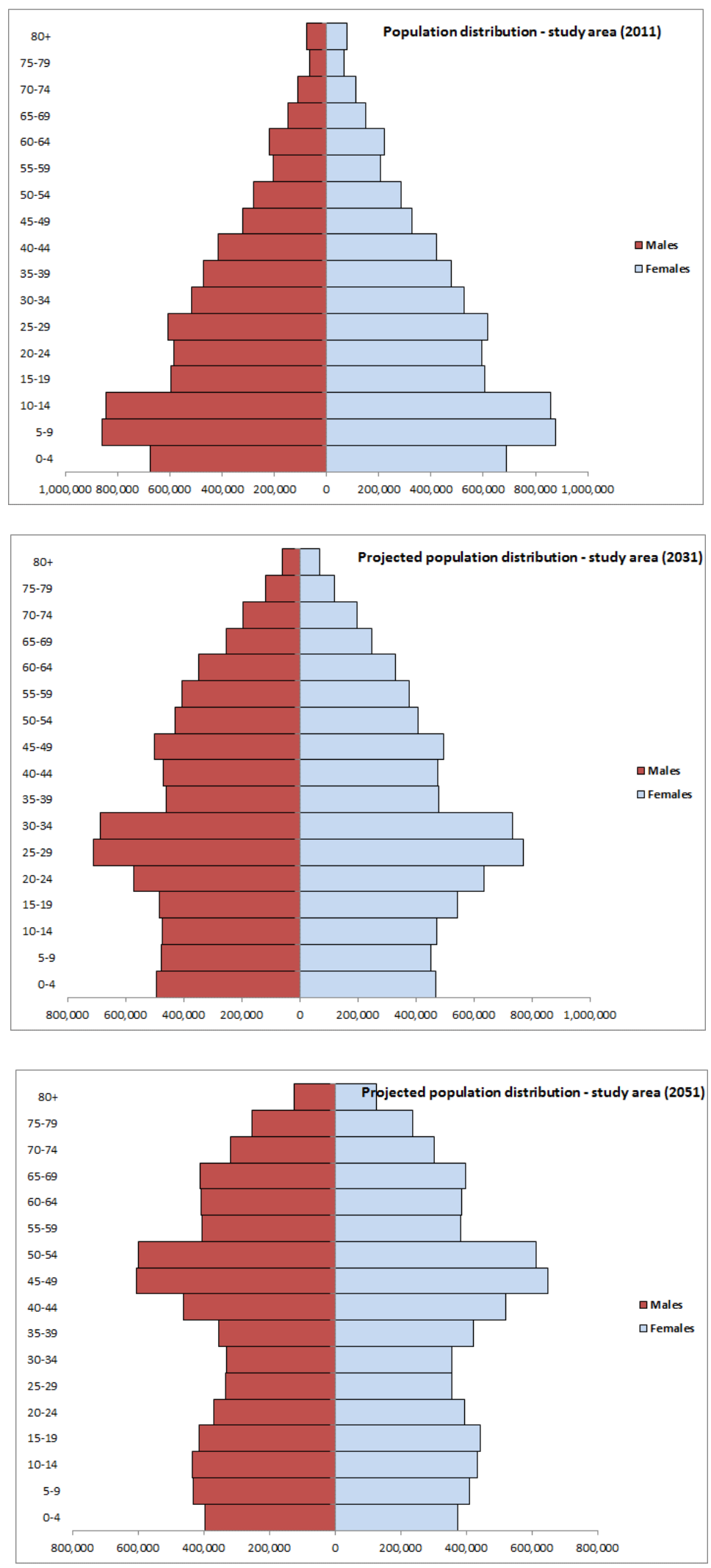

Figure 3: Population pyramids (2011, 2031, 2051). 


\section{CONCLUSIONS AND POLICY IMPLICATIONS}

This study aimed at providing an understanding of future population dynamics with respect to different plausible scenarios in the Ganges Brahmaputra delta of Bangladesh. Several conclusions can be drawn based on our analysis. First, when compared to Bangladesh as a whole, the population of the coastal Ganges Brahmaputra delta shows considerable variability. While overall Bangladesh experiences rapid population growth and high rate of urbanization, the delta region shows different patterns. Due to high out migration combined with declining fertility rates, districts such as Bagerhat have already experienced a considerable decline in their populations. Given high environmental vulnerability of the geographical area under investigation, it is sensible to assume that these patterns are likely to continue thus leading to a general population decline in the region.

The findings of the present study yield important policy implications. First, they suggested a need for tailored district level policy interventions. Second, given the unique demographic patterns in the study area, the policy planning process should prioritize designing specific measures linked to population distribution at the regional and country level. For example the most important policy implication is that linked to the increased percentage of elderly population. Since our projection shows that in the future, the percentage of elderly population is likely to increase, policies regarding healthcare of the elderly should be put in place, along with strengthening local infrastructures. The recent out migration from the coastal GB delta area has an important impact on other geographic locations, including the growth of slums and informal settlements in major cities such as Dhaka, the capital. Finally, given the interconnectedness of environmental and social factors and the present and future impacts of climate change on human wellbeing, it is critical that policy approaches develop integrated strategies targeting the most vulnerable groups.

Future research should aim at understanding the different interrelated drivers of migration, such as political, economic, environmental and social pull and push factors, both at the source and at the destination. Moreover, there is a need for the government and non-governmental organizations to put in place better surveillance 
systems to improve vital statistics database, which would enable studies like this to be more robust with improved access to updated data. 


\section{REFERENCES}

Bangladesh Bureau of Statistics (BBS) (2011) Report on Sample Vital Registration System 2010 (Statistics Division, Ministry of Planning), Dhaka, Bangladesh Bureau of Statistics (BBS).

Bangladesh Bureau of Statistics (BBS), Statistics and Informatics Division (SID), and Ministry of Planning (2012) Population and Housing Census 2011. Socio-economic and demographic report.

Billari, F.C. and Kohler, H.P. (2004) Patterns of low and lowest-low fertility in Europe. Population Studies - a Journal of Demography, 58(2), 161-176. DOI10.1080/0032472042000213695.

Brown, L.R. (2012) Full planet, empty plates: the new geopolitics of food scarcity, W.W. Norton and Company.

CIA (2015) The World Factbook, Central Intelligence Agency, Washington, USA. Retrieved February 2015 from https://www.cia.gov/library/publications/the-world-factbook/

Dyson, T. and Grada, C.O. (2002) Demography, food production and famine risks in the twenty-first century. Institute of Development Studies (IDS) Bulletin, 33(4), 108-113.

Ehrlich, P.R. Ehrlich, A.H. and Daily, G.C. (1993) Food Security, Population, and Environment. Population and Development Review, 19(1), 1-32. DOI $10.2307 / 2938383$.

FAO (2013) Edible insects: Future prospects for food and feed security, Food and Agricultural Organisation of the United Nations. Rome, pp. 201.

FAO, IFAD, and WFP (2013) The State of Food Insecurity in the World 2013. The multiple dimensions of food security, Food and Agriculture Organization of the United Nations (FAO), International Fund for Agricultural Development (IFAD) \& World Food Programme (WFP), Rome, pp. 56.

Funk, C.C. and Brown, M.E. (2009) Declining global per capita agricultural production and warming oceans threaten food security. Food Security, 1(3), 271-289. DOI 10.1007/s12571-009-0026-y.

Hossain, S. Dearing, J. Rahman, M.M. and Salehin, M. (2014) The coevolution of ecosystem services and human wellbeing in the Bangladesh delta. Regional Environmental Change.

Jones, G.W. (2009) Recent Fertility Trends, Policy Responses and Fertility Prospects in Low Fertility Countries of East and Southeast Asia http://www.un.org/esa/population/meetings/EGM-Fertility2009/P05 Jones.pdf.

Malthus, T.R. (1798) "An essay on the principle of population: The first edition (1798) with introduction and bibliography." In E.A. Wrigely and D. Souden (Eds) The Works of Thomas Robert Malthus, Pickering Masters, Vol. 1, William Pickering.

Mitra, S.N., Ali, M.N., Islam, S., Cross, A.R. and Saha, T. (1994) Bangladesh Demographic and Health Survey, 1993-1994. Calverton, Maryland, USA.

MOEF (2005) National Adaptation Programme of Action (NAPA), Final Report. Ministry of Environment and Forest, Government of the People's Republic of Bangladesh, Dhaka.

NIPORT, Mitra and Associates, and ICF International (2013) Bangladesh Demographic and Health Survey 2011, National Institute of Population Research and Training, Mitra and Associates, Measure DHS, ICF International, Dhaka, Bangladesh and Calverton, Maryland, USA. 
Pimentel, D., Huang, X.W., Cordova, A. and Pimentel, M. (1997) Impact of population growth on food supplies and environment. Population and Environment, 19(1), 9-14. DOI 10.1023/A:1024693414602.

Streatfield, P.K. and Karar, Z.A. (2008) Population challenges for Bangladesh in the coming decades. Journal of Health Population and Nutrition, 26(3), 261-272.

Suzuki, T. (2009) Fertility Decline and Governmental Interventions in Eastern Asian Advanced Countries. The Japanese Journal of Population, 7(1), 47-56.

Swapan, M.S.H. and Gavin, M. (2011) A desert in the delta: Participatory assessment of changing livelihoods induced by commercial shrimp farming in Southwest Bangladesh. Ocean \& Coastal Management, 54(1), 45-54. DOI 10.1016/j.ocecoaman.2010.10.011.

UN (2013) World Population Prospects, the 2012 Revision. In United Nations(Ed.)

World Bank (2012) The World Development Indicators Retrieved October 2012 from http://data.worldbank.org/indicator/all 


\section{APPENDIX A}

\section{Projected dependency ratios}

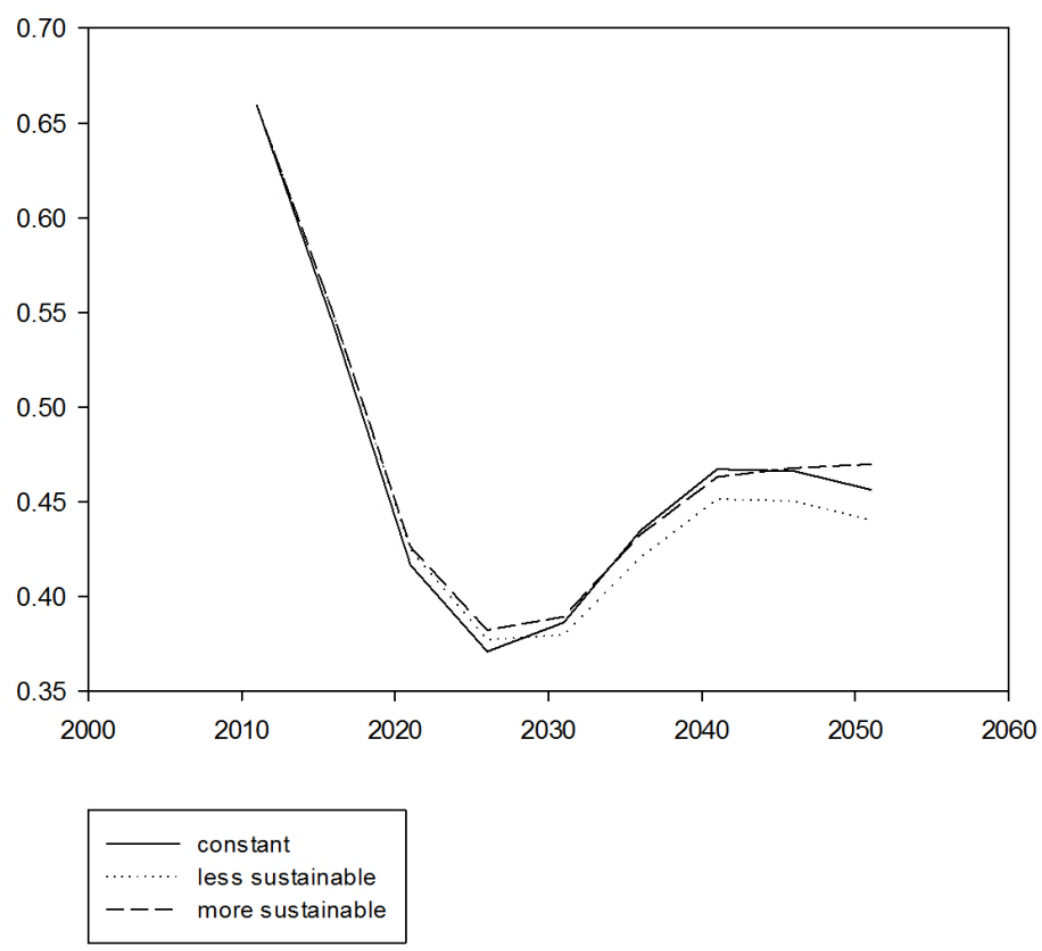

Figure A.1: Estimated dependency ratios in the study area.

Projected median age in the study area

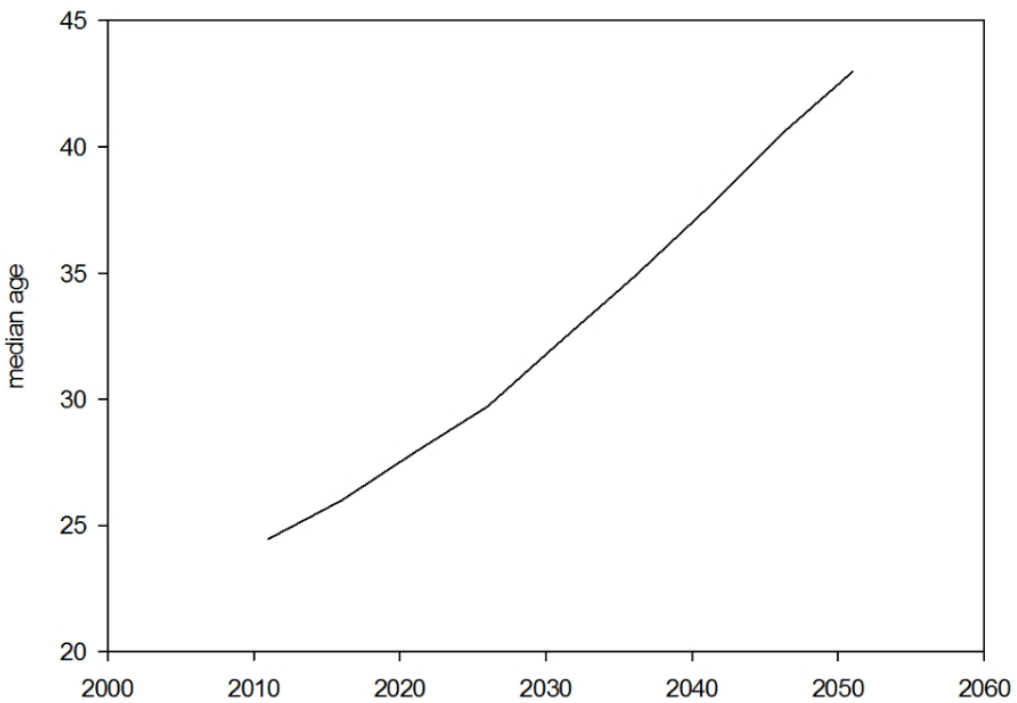

Figure A.2: Estimated median ages in the study area. 
ESRC Centre for Population Change

Building 58, Room 2001

Faculty of Social and Human Sciences

University of Southampton

SO17 1BJ

T: +44 (0)2380 592579

E: cpc@soton.ac.uk

www.cpc.ac.uk

To subscribe to the CPC newsletter and keep up-to-date with research activity, news and events, please register online: www.cpc.ac.uk/newsletter

For our latest research updates you can also follow CPC on Twitter, Facebook and Mendeley:

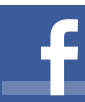

www.facebook.com/CPCpopulation

www.twitter.com/CPCpopulation

ㅇํ www.mendeley.com/groups/3241781/

centre-for-population-change
The ESRC Centre for Population Change (CPC) is a joint initiative between the University of Southampton and a consortium of Scottish universities including St Andrews, Edinburgh, Stirling and Strathclyde, in partnership with the Office for National Statistics and National Records of Scotland.

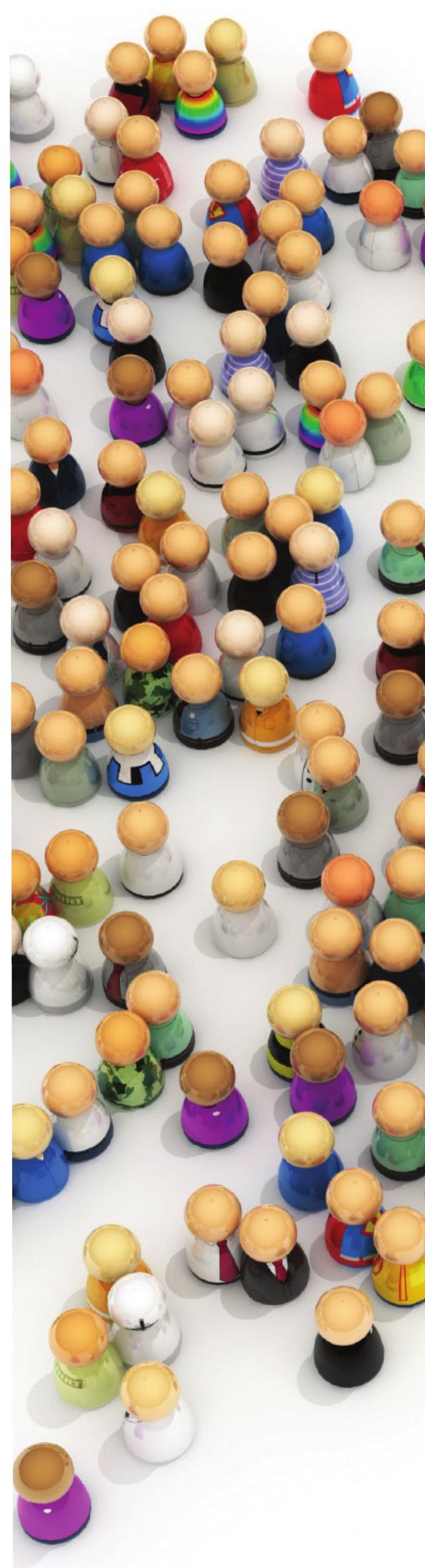

